\title{
Analysis of thromboembolic events in head and neck cancer patients who underwent concurrent chemoradiotherapy with cisplatin: A real-world study
}

Hundo Cho

Department of Hematology-Oncology, Ajou University School of Medicine

\section{Seok Yun Kang}

Department of Hematology-Oncology, Ajou University School of Medicine Hyun Woo Lee

Department of Hematology-Oncology, Ajou University School of Medicine

\section{Yong Won Choi}

Department of Hematology-Oncology, Ajou University School of Medicine

Tae-Hwan Kim

Department of Hematology-Oncology, Ajou University School of Medicine

Mi Sun Ahn ( $\triangle$ maruhiran@hanmail.net)

Department of Hematology-Oncology, Ajou University School of Medicine Jin-Hyuk Choi

Department of Hematology-Oncology, Ajou University School of Medicine

\section{Chul-Ho Kim}

Department of Otolaryngology, Ajou University School of Medicine

\section{Yoo Seob Shin}

Department of Otolaryngology, Ajou University School of Medicine

\section{Jeon Yeob Jang}

Department of Otolaryngology, Ajou University School of Medicine

\section{Young-Taek Oh}

Department of Radiation Oncology, Ajou University School of Medicine Jaesung Heo

Department of Radiation Oncology, Ajou University School of Medicine

\section{Seung Soo Sheen}

Department of Pulmonoay and Critical Care Medicine, Ajou University School of Medicine

\section{Research Article}


Keywords: head and neck cancer, cisplatin, concurrent chemoradiotherapy, Khorana score

Posted Date: February 24th, 2021

DOI: https://doi.org/10.21203/rs.3.rs-233341/v1

License: (c) (1) This work is licensed under a Creative Commons Attribution 4.0 International License. Read Full License 


\section{Abstract \\ Background}

The risk of thromboembolic events (TEE) in cancer patients, especially those receiving cisplatin-based chemotherapy, is higher than that of general population.

\section{Methods}

The study investigated the incidence of TEE in 257 head and neck $(H \& N)$ cancer patients, during or within 6 months of completion of concurrent chemoradiotherapy (CCRT) with cisplatin, and analyzed factors affecting TEE occurrence.

\section{Results}

TEE occurred in 5 patients, an incidence rate of $1.9 \%$. Khorana score was the only factor associated with TEE occurrence $(p=0.010)$.

\section{Conclusions}

The incidence of TEE in H\&N cancer patients who underwent CCRT with cisplatin was relatively low when compared to other types of cancer. However, patients with a high Khorana score require more careful surveillance for possible TEE occurrence.

\section{Introduction}

While malignant tumor cells induce hypercoagulation through several mechanisms, the administration of chemotherapeutic agents may be associated with thrombotic events $(1,2)$. As a result, the risk of thromboembolic events (TEE) in cancer patients is about four times higher than in the general population, and that risk increases up to 6.5 times for patients receiving chemotherapy $(3,4)$. In particular, TEE incidence in various cancer types of patients treated with chemotherapy including cisplatin, one of the most frequently used agents, was reported to be higher compared to those with other regimens (5-9). Moreover, TEE occurrence may affect cancer patients outcomes $(10,11)$.

Head and neck $(\mathrm{H} \& \mathrm{~N})$ cancer refers to malignancy, usually squamous cell carcinoma, in areas such as the nasopharynx, nasal cavity, oropharynx, oral cavity, hypopharynx, and larynx, and incidence is relatively high in many countries $(12,13)$. In locally advanced H\&N cancer, concurrent chemoradiotherapy (CCRT) with cisplatin is the established standard therapy for definitive treatment and adjuvant therapy (14-17). Nonetheless, there are small number of reports regarding the incidence of TEE in H\&N cancer 
with conflicting results, without any real-world study which investigated TEE in patients receiving CCRT with cisplatin (18-20).

For that reason, we investigated the incidence of TEE in H\&N cancer patients who received CCRT with cisplatin, and analyzed the factors affecting TEE occurrence.

\section{Methods}

\section{Study Population}

To begin, all patients who started CCRT with cisplatin for H\&N cancer between January 2005 and December 2019 were retrospectively identified. The eligibility criterion was diagnosis with H\&N squamous cell carcinoma, including other types of carcinoma in cases of nasopharyngeal cancer. Patients who underwent CCRT with cisplatin as definitive therapy following diagnosis or at the time of local recurrence as well as adjuvant therapy after surgical resection, were included in the analysis.

Exclusion criteria included patients with non-squamous histology except for nasopharyngeal cancer; those with distant metastases other than cervical lymph nodes; those who experienced TEE within 3 months prior to initiation of CCRT; those who underwent chemotherapy such as induction therapy before CCRT; those who received other anticancer drugs in addition to cisplatin during CCRT; and those who had started CCRT at other hospitals before continuing of treatment at our institution. Patients with history of chemotherapy for H\&N cancer or other types of cancer were included, with the exception of those who had previously received platinum agents (cisplatin, carboplatin, oxaliplatin).

The study protocol was approved by the Ajou University Hospital Institutional Review Board (IRB No. AJIRB-MED-MDB-20-456).

\section{Clinical Review}

Patient information was collected retrospectively from medical records and radiological reports, including age, gender, smoking history, previous TEE history, cancer site, cancer stage, Eastern Cooperative Oncology Group performance status at the start of CCRT, purpose of CCRT, interval of cisplatin administration, radiation dose, Khorana score, and occurrence of TEE $(21,22)$. Tumor stage classification was based on the American Joint Committee on Cancer 8th edition (23).

For the purpose of this study, TEE was defined as deep vein thrombosis (DVT), pulmonary embolism (PE), other types of venous thrombosis, myocardial infarction, cerebral artery thrombosis, and other types of arterial thrombosis, that occurred during or within 6 months of completion of CCRT. Confirmation of TEE occurrence was based on patient radiological reports, including computerized tomography, magnetic resonance imaging, doppler ultrasonography, and coronary angiography.

During CCRT, cisplatin was usually administered, with a dosage of $100 \mathrm{mg} / \mathrm{m}^{2}$ every 3 weeks for 3 cycles or $30 \mathrm{mg} / \mathrm{m}^{2}$ weekly for 7 weeks. The radiation treatment dose was $200 \mathrm{cGy}$ per day, with a target of 
7000cGy at 35 fractions. Treatment dose and schedule were modified at the discretion of the treating physicians.

\section{Khorana Score}

The Khorana score is a model that predicts the risk of venous thromboembolism (VTE) associated with chemotherapy (22). The score is composed of five clinical and laboratory variables: site of cancer (very high-risk site: 2 points; high-risk site: 1 point); pretreatment leukocyte count (more than $11 \times 10^{9} / \mathrm{L}$ ); pretreatment hemoglobin (less than $10 \mathrm{~g} / \mathrm{dL}$ ) and/or use of erythropoiesis stimulating agents; pretreatment platelet count (more than $350 \times 10^{9} / \mathrm{L}$ ); and body mass index (BMI) of $35 \mathrm{~kg} / \mathrm{m}^{2}$ or more (all 1 point each). H\&N cancer is assigned a score of 0 at the cancer site.

\section{Statistical analysis}

Continuous variables are presented as mean \pm standard deviation and categorical variables as frequencies and percentages. Comparisons of continuous and categorical variables were performed by Mann-Whitney test and Fisher's exact test, respectively. All statistical analyses were two-sided and performed using SPSS version 23.0 for Windows.

\section{Results}

Of the $265 \mathrm{H} \& \mathrm{~N}$ cancer patients who underwent CCRT with cisplatin during the study period, 257 patients were included in the analysis while 8 patients were excluded for the following reasons: previous history of chemotherapy including platinum (4 patients); history of TEE within 3 months before the start of treatment (2 patients); salivary gland adenocarcinoma (1 patient); and induction chemotherapy before CCRT (1 patient).

Table 1 summarizes the clinical characteristics of all patients and those with occurrence of TEE. Of the 257 eligible patients, 224 (87.2\%) were under the age of 70 years, with a median age of $59(18 \sim 78)$, and 219 (85.2\%) were male. The most prevalent cancer site was the nasopharynx (72 patients/28.6\%), and the most common stage was IV (124 patients/48.2\%). TEE occurred in 5 patients (1.9\%), with no significant association between the incidence of TEE and clinical characteristics. Among patients with TEE occurrence, Khorana score were 0 (2 patients), 1 (1 patient), and 2 (2 patients), with a significant correlation between TEE and Khorana score $(p=0.010)$ (Table 1). 
Table 1

Patients characteristics and their relationship with thromboembolic events

\begin{tabular}{|c|c|c|c|c|}
\hline \multirow[t]{2}{*}{ Characteristics } & \multirow{2}{*}{$\begin{array}{l}\text { Total } \\
\text { N (\%) }\end{array}$} & \multicolumn{2}{|l|}{ TEE incidence } & \multirow[t]{2}{*}{$P$ value } \\
\hline & & Non-TEE cases & TEE cases & \\
\hline Total patients & $257(100)$ & 252 & 5 & \\
\hline Age (years) & & & & 0.125 \\
\hline$<70$ & $224(87.2)$ & 221 (87.7) & $3(60.0)$ & \\
\hline$\geq 70$ & $33(12.8)$ & $31(12.3)$ & $2(40.0)$ & \\
\hline Gender & & & & 0.554 \\
\hline Male & 219 (85.2) & $215(85.3)$ & $4(80.0)$ & \\
\hline Female & $38(14.8)$ & $37(14.7)$ & $1(20.0)$ & \\
\hline Cancer sites & & & & 0.169 \\
\hline Nasopharynx & $72(28.0)$ & $72(28.6)$ & $0(0.0)$ & \\
\hline Nasal cavity & $10(3.9)$ & $9(3.6)$ & $1(20.0)$ & \\
\hline Oropharynx & $72(28.0)$ & $69(27.4)$ & $3(60.0)$ & \\
\hline Oral cavity & 35 (13.6) & $34(13.5)$ & $1(20.0)$ & \\
\hline Hypopharynx & $35(13.6)$ & 35 (13.9) & $0(0.0)$ & \\
\hline Larynx & $30(11.7)$ & $30(11.9)$ & $0(0.0)$ & \\
\hline Salivary gland & $1(0.4)$ & $1(0.4)$ & $0(0.0)$ & \\
\hline Unknown primary site & $2(0.8)$ & $2(0.8)$ & $0(0.0)$ & \\
\hline Cancer stage $\mathrm{e}^{\mathrm{a}}$ & & & & 0.626 \\
\hline I & $21(8.2)$ & $21(8.3)$ & $0(0.0)$ & \\
\hline II & $36(14.0)$ & $36(14.3)$ & $0(0.0)$ & \\
\hline III & $47(18.3)$ & $47(18.7)$ & $0(0.0)$ & \\
\hline
\end{tabular}

TEE, thromboembolic events; ECOG, Eastern Cooperative Oncology Group; cGy, centigray; N, number of patients

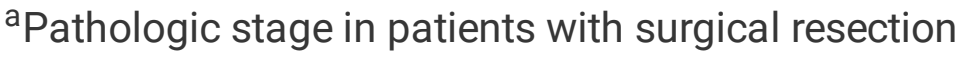

${ }^{\mathrm{b}}$ Current smoker (67); former smoker (75)

Including the 16 patients who underwent adjuvant CCRT after resection of locally recurrent lesion(s) 


\begin{tabular}{|c|c|c|c|c|}
\hline \multirow[t]{2}{*}{ Characteristics } & \multirow{2}{*}{$\begin{array}{l}\text { Total } \\
\text { N (\%) }\end{array}$} & \multicolumn{2}{|l|}{ TEE incidence } & \multirow[t]{2}{*}{$P$ value } \\
\hline & & Non-TEE cases & TEE cases & \\
\hline IV & $124(48.2)$ & $120(47.6)$ & $4(80.0)$ & \\
\hline Local recurrence & $29(11.3)$ & $28(11.1)$ & $1(20.0)$ & \\
\hline ECOG Performance state & & & & 1.000 \\
\hline 0,1 & $235(91.4)$ & 230 (91.3) & $5(100.0)$ & \\
\hline 2,3 & $22(8.6)$ & $22(8.7)$ & $0(0.0)$ & \\
\hline Smoking history & & & & 0.176 \\
\hline No & $115(44.7)$ & $111(44.0)$ & $4(80.0)$ & \\
\hline Yes & $142(55.3)^{b}$ & $141(56.0)$ & $1(20.0)$ & \\
\hline TEE history & & & & 1.000 \\
\hline No & $240(93.4)$ & 235 (93.3) & $5(100.0)$ & \\
\hline Yes & $17(6.6)$ & $17(6.7)$ & $0(0.0)$ & \\
\hline Purpose of CCRT & & & & 0.677 \\
\hline Definitive treatment & $132(51.4)$ & $130(51.6)$ & $2(40.0)$ & \\
\hline Adjuvant CCRT & $125(48.6)^{c}$ & $122(48.4)$ & $3(60.0)$ & \\
\hline Cisplatin interval & & & & 0.283 \\
\hline 3weeks interval & $203(79.0)$ & $200(79.4)$ & $3(60.0)$ & \\
\hline Weekly & $54(21.0)$ & $52(20.6)$ & $2(40.0)$ & \\
\hline Cumulative radiation dose, cGy & $6458.0 \pm 843.1$ & $6455.6 \pm 850.8$ & $6580.0 \pm 238.7$ & 0.677 \\
\hline Khorana score & & & & 0.010 \\
\hline 0 & 198 (77.0) & $196(77.8)$ & $2(40.0)$ & \\
\hline 1 & $50(19.5)$ & 49 (19.4) & $1(20.0)$ & \\
\hline
\end{tabular}

TEE, thromboembolic events; ECOG, Eastern Cooperative Oncology Group; cGy, centigray; N, number of patients

apathologic stage in patients with surgical resection

${ }^{\mathrm{b}}$ Current smoker (67); former smoker (75)

Including the 16 patients who underwent adjuvant CCRT after resection of locally recurrent lesion(s) 


\begin{tabular}{|c|c|c|c|c|}
\hline \multirow[t]{2}{*}{ Characteristics } & \multirow{2}{*}{$\begin{array}{l}\text { Total } \\
\mathbf{N}(\%)\end{array}$} & \multicolumn{2}{|l|}{ TEE incidence } & \multirow[t]{2}{*}{$P$ value } \\
\hline & & Non-TEE cases & TEE cases & \\
\hline 2 & $8(3.1)$ & $6(2.4)$ & $2(40.0)$ & \\
\hline 3 & $1(0.4)$ & $1(0.4)$ & $0(0.0)$ & \\
\hline
\end{tabular}

TEE, thromboembolic events; ECOG, Eastern Cooperative Oncology Group; cGy, centigray; N, number of patients

aPathologic stage in patients with surgical resection

${ }^{\mathrm{b} C u r r e n t ~ s m o k e r ~(67) ; ~ f o r m e r ~ s m o k e r ~(75) ~}$

Including the 16 patients who underwent adjuvant CCRT after resection of locally recurrent lesion(s)

Types of TEE included DVT alone (3 patients/60\%), simultaneous occurrence of DVT and PE (1 patient/20\%), and arterial thrombosis (common carotid artery) (1 patient/20\%) (Table 2).

Table 2

Types of thromboembolic events

\begin{tabular}{|ll|}
\hline \multicolumn{1}{|l|}{} & Number of patients (\%) \\
\hline TEE & 5 \\
\hline Types & $3(60.0)$ \\
\hline DVT alone & $1(20.0)$ \\
\hline DVT + PE & $1(20.0)$ \\
\hline Arterial thrombosis & \\
\hline TEE, thromboembolic events; DVT, deep vein thrombosis; PE, pulmonary embolism \\
\hline
\end{tabular}

\section{Discussion}

To our knowledge, the present study is the first to investigate the incidence of TEE in H\&N cancer patients who underwent CCRT with cisplatin in real-world practice. The observed incidence of TEE was $1.9 \%$, and Khorana score was the only factor associated with the risk of TEE.

In cancer patients, various risk factors increase the incidence of TEE. Among patient-related factors, TEE is known to be associated with age, obesity, thrombocytosis, leukocytosis, hemoglobin $<10 \mathrm{~g} / \mathrm{dL}$ before chemotherapy, and a history of previous TEE $(22,24)$. Treatment-related factors such as chemotherapy are also associated with risk of TEE (2). 
Conflicting results have been reported regarding the incidence of TEE in $\mathrm{H} \& \mathrm{~N}$ cancer patients. According to one meta-analysis, the incidence of VTE in H\&N cancer patients was $0.16-3.13 \%$ (18). Incidence of VTE in $\mathrm{H} \& \mathrm{~N}$ cancer patients after surgery is generally low $(0 \sim 8 \%)$, although one study reported higher rate of $26.3 \%(18,20)$. While one study reported that $\mathrm{H} \& \mathrm{~N}$ cancer is the least common type of cancer diagnosed following VTE, another large study identified H\&N cancer as the second highest risk for VTE among 18 types of carcinoma $(18,19)$. In a large population-based study, the incidence of TEE in noncancer population was $1.4 \%$, which is similar to the rate of occurrence among $\mathrm{H} \& \mathrm{~N}$ cancer patients reported in several studies $(18,25)$.

In the present study, the observed incidence rate of TEE was $1.9 \%$, which is not that dissimilar to the rate in the general population and aligns with previous studies regarding the incidence of TEE in H\&N cancer (18). However, most previous studies of TEE in H\&N cancer analyzed heterogenous populations consisting mainly of a surgical treatment alone group, with small number of reports about patients who received chemotherapy including various regimens $(18,20)$. The present study investigated patients who underwent CCRT with cisplatin, which is the essential chemotherapeutic agent for management of H\&N cancer. Although the mechanism of cisplatin-induced hypercoagulability is not entirely clear, several studies have proposed possible pathophysiologic processes; these include impaired autoregulation of the vascular system, an altered balance between thrombosis and fibrinolysis, direct endovascular damage, increased procoagulant activity of red blood cells, and modulation of tissue factor on human monocytes (26-28).

There have been several reports of increased TEE incidence in patients treated with cisplatin-based regimens. Among these, Russell et al. reported an $18.1 \%$ incidence of TEE related to cisplatin-based chemotherapy in 932 patients with various types of malignancy (8). The reported incidence of TEE in non-small cell lung cancer patients who underwent a cisplatin-based regimen was $8.0 \sim 17.6 \%$, with $10.2 \%$ of the 1-year incidence rate of TEE in small cell lung cancer patients treated with cisplatin-based chemotherapy $(5-7,29)$. In the present study, the incidence of TEE in H\&N cancer patients during or after CCRT with cisplatin seems to be low when compared to patients with other types of cancer who received cisplatin-based regimens. A larger-scale study is required to determine the possible explanation for these findings.

In the present study, one interesting result is the significant association between the TEE occurrence and Khorana score despite of the low incidence of TEE itself. As a means of predicting the risk of chemotherapy-associated thrombosis in cancer patients, the Khorana scoring system has some limitations. For example, since $\mathrm{BMl}>35 \mathrm{~kg} / \mathrm{m}^{2}$ is rare among Asian patients, accurate evaluation is difficult $(5,30)$. In the present study cohort, only one patient $(0.4 \%)$ had a BMI of $>35 \mathrm{~kg} / \mathrm{m}^{2}$, which figure was not significantly different from that of the previous Asian study $(5,30)$. Nonetheless, Khorana score was the only factor associated with the TEE incidence in present study. Therefore, in cases of H\&N cancer patients with high Khorana score receiving cisplatin-CCRT, treating physician should be aware of possible TEE occurrence during or for a period of time after CCRT. In addition, these patients should be informed about the somewhat higher risk of TEE before starting treatment. 
The current study has several limitations. As a retrospective study based on a review of medical records, selection bias may occur, resulting in possible underestimation of TEE incidence. The small number of patients with TEE means that statistically significant results are less reliable, especially in terms of the relationship between TEE incidence and clinical characteristics. Finally, the present study cohort comprised patients from a single institution over a fairly long period. Nevertheless, this study seems to be clinically meaningful because it investigated all patients during the defined period who underwent CCRT with cisplatin, which is the mainstay of treatment for locally advanced $\mathrm{H} \& \mathrm{~N}$ cancer, reflecting real-world clinical practice in Korea.

In conclusion, while the incidence of TEE in H\&N cancer patients who underwent CCRT with cisplatin was relatively low (1.9\%) when compared to other types of cancer, patients with a high Khorana score require more careful surveillance for possible occurrence of TEE.

\section{Abbreviations}

TEE: thromboembolic event; H\&N: head and neck; CCRT: concurrent chemoradiotherapy; DVT: deep vein thrombosis; PE: pulmonary embolism; VTE: venous thromboembolism; BMI: body mass index;

\section{Declarations}

\section{Ethics approval and consent to participate}

The protocol was reviewed and approved by the Institutional Review Board of Ajou University Hospital (IRB approval no. AJIRB-MED-MDB-20-456). Informed consent was waived by the same ethics committee that approved the study (Institutional Review Board of Ajou University Hospital). In present study, all methods were performed in accordance with the relevant guidelines and regulations.

\section{Consent for publication}

Not applicable

\section{Availability data and materials}

The datasets generated and/or analyzed during the current study are not publicly available due to the confidentiality of the data of patient but are available from the corresponding authors on reasonable request.

\section{Competing interests}

The authors declare no competing interests.

\section{Funding}


This research received no specific grant from any funding agency in the public, commercial, or not-forprofit sectors.

\section{Authors' contributions}

HC, SYK, HWL, YWC, THK, MSA, JHC, CHK, YSS, JYJ, YTO, and JH collected and analyzed clinical data. $\mathrm{HC}$ wrote the main manuscript. $\mathrm{HC}, \mathrm{JHC}, \mathrm{MSA}$ and SSS performed statistical analysis. All authors read and approved the final manuscript.

\section{Acknowledgments}

Not applicable.

\section{References}

1. Falanga A, Russo L, Milesi V, Vignoli A. Mechanisms and risk factors of thrombosis in cancer. Crit Rev Oncol Hematol. 2017;118:79-83.

2. Haddad TC, Greeno EW. Chemotherapy-induced thrombosis. Thromb Res. 2006;118(5):555-68.

3. Heit JA, Silverstein MD, Mohr DN, Petterson TM, O'Fallon WM, Melton LJ, III. Risk Factors for Deep Vein Thrombosis and Pulmonary Embolism: A Population-Based Case-Control Study. Arch Intern Med. 2000;160(6):809-15.

4. Blom JW, Doggen CJ, Osanto S, Rosendaal FR. Malignancies, prothrombotic mutations, and the risk of venous thrombosis. JAMA. 2005;293(6):715-22.

5. Lee YG, Lee E, Kim I, Lee KW, Kim TM, Lee SH, et al. Cisplatin-Based Chemotherapy Is a Strong Risk Factor for Thromboembolic Events in Small-Cell Lung Cancer. Cancer Res Treat. 2015;47(4):670-5.

6. Mellema WW, van der Hoek D, Postmus PE, Smit EF. Retrospective evaluation of thromboembolic events in patients with non-small cell lung cancer treated with platinum-based chemotherapy. Lung Cancer. 2014;86(1):73-7.

7. Numico G, Garrone O, Dongiovanni V, Silvestris N, Colantonio I, Di Costanzo G, et al. Prospective evaluation of major vascular events in patients with nonsmall cell lung carcinoma treated with cisplatin and gemcitabine. Cancer. 2005;103(5):994-9.

8. Moore RA, Adel N, Riedel E, Bhutani M, Feldman DR, Tabbara NE, et al. High incidence of thromboembolic events in patients treated with cisplatin-based chemotherapy: a large retrospective analysis. J Clin Oncol. 2011;29(25):3466-73.

9. Seng S, Liu Z, Chiu SK, Proverbs-Singh T, Sonpavde G, Choueiri TK, et al. Risk of venous thromboembolism in patients with cancer treated with Cisplatin: a systematic review and metaanalysis. J Clin Oncol. 2012;30(35):4416-26.

10. Chew HK, Wun T, Harvey D, Zhou H, White RH. Incidence of venous thromboembolism and its effect on survival among patients with common cancers. Arch Intern Med. 2006;166(4):458-64. 
11. Kuderer NM, Francis CW, Culakova E, Khorana AA, Ortel T, Falanga A, et al. Venous thromboembolism and all-cause mortality in cancer patients receiving chemotherapy. J Clin Oncol. 2008;26(15_suppl):9521-.

12. Ferlay J, Soerjomataram I, Dikshit R, Eser S, Mathers C, Rebelo M, et al. Cancer incidence and mortality worldwide: sources, methods and major patterns in GLOBOCAN 2012. Int J Cancer. 2015;136(5):E359-86.

13. Siegel RL, Miller KD, Jemal A. Cancer statistics, 2018. CA Cancer J Clin. 2018;68(1):7-30.

14. Porceddu SV, Campbell B, Rischin D, Corry J, Weih L, Guerrieri M, et al. Postoperative chemoradiotherapy for high-risk head-and-neck squamous cell carcinoma. Int J Radiat Oncol Biol Phys. 2004;60(2):365-73.

15. Bernier J, Domenge C, Ozsahin M, Matuszewska K, Lefèbvre J-L, Greiner RH, et al. Postoperative irradiation with or without concomitant chemotherapy for locally advanced head and neck cancer. $\mathrm{N}$ Engl J Med. 2004;350(19):1945-52.

16. Adelstein DJ, Li Y, Adams GL, Wagner Jr H, Kish JA, Ensley JF, et al. An intergroup phase III comparison of standard radiation therapy and two schedules of concurrent chemoradiotherapy in patients with unresectable squamous cell head and neck cancer. J Clin Oncol. 2003;21(1):92-8.

17. Forastiere AA, Zhang Q, Weber RS, Maor MH, Goepfert H, Pajak TF, et al. Long-term results of RTOG 91 - 11: a comparison of three nonsurgical treatment strategies to preserve the larynx in patients with locally advanced larynx cancer. J Clin Oncol. 2013;31(7):845.

18. Haen P, Mege D, Crescence L, Dignat-George F, Dubois C, Panicot-Dubois L. Thrombosis Risk Associated with Head and Neck Cancer: A Review. Int J Mol Sci. 2019;20(11).

19. Paneesha S, McManus A, Arya R, Scriven N, Farren T, Nokes T, et al. Frequency, demographics and risk (according to tumour type or site) of cancer-associated thrombosis among patients seen at outpatient DVT clinics. Thromb Haemost. 2010;103(02):338-43.

20. Kakei Y, Akashi M, Hasegawa T, Minamikawa T, Usami S, Komori T. Incidence of Venous Thromboembolism After Oral Oncologic Surgery With Simultaneous Reconstruction. J Oral Maxillofac Surg. 2016;74(1):212-7.

21. Sørensen J, Klee M, Palshof T, Hansen H. Performance status assessment in cancer patients. An inter-observer variability study. Br J Cancer. 1993;67(4):773-5.

22. Khorana AA, Kuderer NM, Culakova E, Lyman GH, Francis CW. Development and validation of a predictive model for chemotherapy-associated thrombosis. Blood. 2008;111(10):4902-7.

23. Lydiatt WM, Patel SG, O'Sullivan B, Brandwein MS, Ridge JA, Migliacci JC, et al. Head and Neck cancers-major changes in the American Joint Committee on cancer eighth edition cancer staging manual. CA Cancer J Clin. 2017;67(2):122-37.

24. Kröger K, Weiland D, Ose C, Neumann N, Weiss S, Hirsch C, et al. Risk factors for venous thromboembolic events in cancer patients. Ann Oncol. 2006;17(2):297-303.

25. Khorana AA, Dalal M, Lin J, Connolly GC. Incidence and predictors of venous thromboembolism (VTE) among ambulatory high-risk cancer patients undergoing chemotherapy in the United States. 
Cancer. 2013;119(3):648-55.

26. LÜ C-f, Yu H-j, Hou J-x, Jin Z. Increased procoagulant activity of red blood cells in the presence of cisplatin. Chin Med J. 2008;121(18):1775-80.

27. Jafri M, Protheroe A. Cisplatin-associated thrombosis. Anti-cancer drugs. 2008;19(9):927-9.

28. Walsh J, Wheeler HR, Geczy CL. Modulation of tissue factor on human monocytes by cisplatin and adriamycin. Br J Haematol. 1992;81(4):480-8.

29. Chew HK, Davies AM, Wun T, Harvey D, Zhou H, White RH. The incidence of venous thromboembolism among patients with primary lung cancer. J Thromb Haemost. 2008;6(4):601-8.

30. Aonuma AO, Nakamura M, Sakamaki K, Murai T, Matsuda C, Itaya K, et al. Incidence of cancerassociated thromboembolism in Japanese gastric and colorectal cancer patients receiving chemotherapy: a single-institutional retrospective cohort analysis (Sapporo CAT study). BMJ Open. 2019;9(8):e028563. 